ORIGINAL RESEARCH ARTICLE

\title{
Cost-Effectiveness Analysis of Family Planning Services Offered by Mobile Clinics versus Static Clinics in Assiut, Egypt
}

\author{
Ghada S.T. Al-Attar ${ }^{* 1}$, David Bishai ${ }^{2}$,Omaima El-Gibaly ${ }^{1}$ \\ Department of Public Health and Community Medicine, Faculty of Medicine, Assiut University, Assiut, Egypt ${ }^{1}$; Department of \\ Population, Family \& Reproductive Health, Johns Hopkins School of Public Health, Baltimore, Maryland, USA ${ }^{2}$.
}

*For Correspondence: E-mail: galattar20@gmail.com; Phone: +201015061606

\begin{abstract}
Cost effectiveness studies of family planning (FP) services are very valuable in providing evidence-based data for decision makers in Egypt. Cost data came from record reviews for all 15 mobile clinics and a matched set of 15 static clinics and interviews with staff members of the selected clinics at Assiut Governorate. Effectiveness measures included couple years of protection (CYPs) and FP visits. Incremental cost-effectiveness ratios (ICER) and sensitivity analyses were calculated. Mobile clinics cost more per facility, produced more CYPs but had fewer FP visits. Sensitivity analysis was done using: total costs, CYP and FP visits of mobile and static clinics and showed that variations in CYP of mobile and static clinics altered the ICER for CYP from \$2 $-\$ 6$. Mobile clinics with their high emphasis on IUDs offer a reasonable cost effectiveness of $\$ 4.46$ per additional CYP compared to static clinics. The ability of mobile clinics to reach more vulnerable women and to offer more long acting methods might affect a policy decision between these options. Static clinics should consider whether emphasizing IUDs may make their services more cost-effective. (Afr J Reprod Health 2017; 21[1]: 30-38).
\end{abstract}

Keywords: Mobile clinics; Staic clinic; Family planning; Cost-effectiveness

\section{Résumé}

Des analyses coût-efficacité de la planification familiale $(\mathrm{PF})$ de services sont très utiles pour fournir des données probantes pour les décideurs en Égypte. Les données proviennent de coûts des examens pour l'ensemble des 15 cliniques mobiles et un ensemble assorti de 15 cliniques et des entrevues avec des membres du personnel des cliniques juridiques dans le gouvernorat d'Assiout. L'efficacité des mesures prévues années de protection (CYP) et du programme de visites. Les rapports coût-efficacité différentiel (RCED) et des analyses de sensibilité ont été calculés. Les cliniques mobiles plus coût par installation, produit plus CYPs mais ont eu moins de visites de PF. Analyse de sensibilité a été effectuée à l'aide : total des coûts, CYP et FP de visites cliniques mobiles et statiques et a montré que les variations de CYP de cliniques mobiles et statiques modifié le RCED DU CYP à partir de $\$ 2$ - \$6. Les cliniques mobiles avec leur accent sur le DIU offrent un coût raisonnable efficacité de 4,46 \$ par CYP supplémentaires par rapport aux cliniques. La capacité des cliniques mobiles pour atteindre les femmes les plus vulnérables et d'offrir plus de méthodes de longue durée d'action peut influer sur une décision politique entre ces options. Cliniques devraient se demander si l'accent sur les DIU peuvent rendre leurs services plus rentables. (Afr J Reprod Health 2017; 21 [1]: 30-38).

Mots-clés: Les cliniques mobiles ; la planification familiale ; le rapport coût-efficacité.

\section{Introduction}

Outreach clinical services, like mobile clinics, can reduce health disparities by providing services to clients living in remote rural areas, without nearby facilities $^{1-3}$. In Egypt, "Mobile Clinics" project was started in 1997 to provide many services including no-fee family planning/reproductive health services for areas lying 3 kilometers from the nearest health unit. However, the resources are growing more slowly than demand for family planning services and goods ${ }^{4}$. A recent study in Assiut Governorate revealed surprisingly low use of mobile clinic services among women who were living at the remote rural areas (satellites); $5.5 \%$ of contraceptive users at the time of the survey got their services from the mobile clinic ${ }^{5}$. The results of that study confirmed other evidence from the Egyptian Demographic and Health Surveys (EDHSs) 2005, 2008 and 2014 showing that mobile clinics were a less common source of contraceptive methods than static clinics ${ }^{6-8}$. 
The objectives of this study were to compare cost effectiveness of family planning services offered by the mobile clinics versus the static clinics and to measure the incremental cost effectiveness ratio (ICER) for couple years of protection (CYP). The results of this study may guide policy makers interested in the efficiency of family planning outreach activities and help Family Planning (FP) directors in decision making concerning the operational policy of mobile clinics in Assiut Governorate.

\section{Methods}

Assiut Governorate lies $375 \mathrm{~km}$ south of Cairo. In Assiut governorate, there are 15 mobile clinics which started working since 1997 to offer family planning/ reproductive services to women living at the remote underserved areas (satellites and some villages). The 15 mobile clinics are distributed to cover all the districts of Assiut Governorate. One clinic is assigned to each district except for the higher density population districts e.g. Assiut, Dayerout, Al-Quoseya, Manfalout where 2 clinics are assigned to serve each of these districts. Each clinic has to achieve a circuit of 22 site visits per month; each site visit lasts from 8.00 a.m. until 4.00 p.m. with an accompanying female physician, nurse and a driver". The managerial system of the mobile clinic in Assiut Governorate is under the supervision of the family planning directorate who puts monthly and three-month plans for the mobile clinics timetable. The operational policy at the local level matches the operational policy of the mobile clinics at the central level ${ }^{4}$.

Cost and effectiveness data were based on a Ministry of Health and Population (MOHP) record review and meetings with medical and paramedical team personnel who were working at the mobile and static clinics from the first of November, 2009 to the end of October, 2010. This time horizon was chosen instead of having a whole calendar year from January to December because the working hours and road map of the mobile clinics were changed at the beginning of November, 2010. All 15 working mobile clinics in Assiut Governorate were included in the study. In addition, interviews were held with all the drivers working at the mobile clinics to estimate fuels and transport costs. As the research was mainly focusing on cost-effectiveness of the service and related policy changes, thus provider perspective was the main focus.

For each district of Assiut Governorate that was served by mobile clinics, one matching static clinic was chosen at random from a list of all static family planning clinics for that district. Matching was done based on the availability of family planning services offered at the static clinic in the same district where the mobile clinic serves by the same medical and paramedical health care providers offering the same services at the mobile clinics. If the closest village did not contain a static clinic (rural health unit), the next closest health unit was then selected. Approvals were obtained from the MOHP authorities at the central office in Cairo and from the peripheral level at Assiut Governorate. Data were collected on the salaries and number of health workers of each cadre, quantities and costs of supplies and materials of FP clinics, types and number of contraceptive methods dispensed from the static clinics, types of services and number of client visits according to each service offered, and number of new and old FP clients to each static clinic.

Cost measures were collected from a provider point of view. Cost data from the different district records included salaries and incentives of the health team personnel, contraceptive methods' costs, capital costs, supplies and materials' costs, operating costs and maintenance costs for both mobile and static clinics in addition to fuel and oil costs for the mobile clinics. Costs were expressed in local currency then converted into US \$ according to the exchange rate for the year 2010 as most of the collected data belong to the year 2010 . A 3\% discount rate was used.

\section{Cost measures}

During their daily work at the mobile and static clinics, the health team members offered many services to the clinic attendants other than family planning services, so, only a portion of their salaries were allocated to family planning services. The salary allocation was calculated based on calculating the percent of time spent by each health worker at the clinic offering family planning 
services. Time allocation was measured based on interviews with each health worker.

After obtaining the number of family planning commodities dispensed within each mobile and static clinic from November 2009 till October 2010, the total commodities costs were calculated using the following formula:

Total commodities cost $=\sum_{\mathrm{i}}$ Commodity $_{\mathrm{i}} \times$ Unit Cost $_{\mathrm{i}}$

Where: "i" is an index for each method type, Commodity $_{i}$ is the count of dispensed family planning methods of type " $i$ " from November 2009 to October 2010. This was calculated for each type of method and for each mobile and static clinic; then the grand total costs were calculated by summing all costs of each type of clinic. The lists of the different types of family planning methods, the degree of subsidy as well as the unit cost of each contraceptive method are shown in Table (1).

Table 1: Unit Cost and Unit price of Contraceptive Methods at the Mobile and Static Clinics, Assiut, Egypt, November 2009 to October 2010.

\begin{tabular}{|c|c|c|c|}
\hline \multirow{2}{*}{$\begin{array}{l}\text { Contraceptive } \\
\text { method }\end{array}$} & \multirow{2}{*}{$\begin{array}{l}\text { Unit cost } \\
\text { used in the } \\
\text { analysis } \\
\text { (US \$) }\end{array}$} & \multicolumn{2}{|c|}{$\begin{array}{l}\text { Unit price paid by } \\
\text { patient }\end{array}$} \\
\hline & & $\begin{array}{l}\text { Mobile } \\
\text { clinic }\end{array}$ & Static clinic \\
\hline IUD & $\$ 0.6$ & $\begin{array}{l}\text { Free of } \\
\text { charge }\end{array}$ & $\$ 0.4$ \\
\hline $\begin{array}{l}\text { Birth Control } \\
\text { Pills }\end{array}$ & $\$ 0.17-0.54$ & $\$ 0.2$ & $\begin{array}{l}\$ \quad 0.12 \\
0.18^{*}\end{array}$ \\
\hline Injectable & $\$ 1.4$ & $\begin{array}{l}\text { Free of } \\
\text { charge }\end{array}$ & $\$ 0.2$ \\
\hline Condoms & $\$ 0.1$ & $\begin{array}{l}\text { Free of } \\
\text { charge }\end{array}$ & $\$ 0.02$ \\
\hline Implants & $\$ 37.2$ & $\mathrm{NA} * *$ & $\$ 0.9$ \\
\hline
\end{tabular}

* There are 2 types of pills offered in the static clinics; levonor minipills which cost US $\$ 0.54$ per 28 day dose and are sold at US \$ 0.2 per unit, while compound pills cost US $\$ 0.17$ per 28 day dose and are sold T US $\$ 0.12$ per unit for clients. At the mobile clinics, levonor minipills are the only type of pills that are dispensed for clients.

** NA $=$ Non applicable as no capsules are applied to women in the mobile clinics.

The operating costs included maintenance costs for all mobile and all static clinics plus fuel and transport costs for all mobile clinics only. A monthly average estimate for the maintenance cost was obtained for both the mobile and the static clinics and multiplied by 12 months. The total number of kilometers traveled by each mobile clinic was used to estimate fuel costs as follows:

$$
\text { Cost }_{\text {fuel }}=\mathrm{km} \times \frac{\text { Liters }}{\mathrm{km}} \times \frac{\text { Cost }}{\text { Liter }}
$$

The grand total fuel costs were aggregated for all mobile clinics. The average quantities for the different supplies and materials were obtained for each type of clinic; static and mobile per month then they were multiplied by 12 months to estimate the annual costs for mobile and static clinics.

The capital costs of the mobile clinic were annualized from the following formula:

\section{Annual Capital Costs of mobile clinic $=$ replacement costs of 1 clinic \\ $\times$ number of clinics \\ $\times$ depreciation rate}

The replacement cost is the current cost of purchasing a similar vehicle, not the original purchase price ${ }^{10}$. The replacement cost of one mobile clinic was obtained from the FP Director at Assiut Governorate while the depreciation rate was based upon previous studies ${ }^{4}$. The depreciation rate was approximated at $1 /$ useful life and the useful life of a mobile clinic was determined to be 20 years.

The annual capital costs of the static clinics were calculated using the following formula:

Annual capital costs per static clinic

$=$ Monthly Rental costs of the clinic per month $\times 12$

\section{Effectiveness measures}

This single study determined CYPs and visits for the various FP modalities as effectiveness measures. Total FP visits were calculated for all mobile and selected static clinics. As for CYPs, total units dispensed of different types of contraceptive methods at each clinic were calculated first then CYPs were calculated based on Egypt MOHP coefficients ${ }^{11}$ :

IUD $=3.2 \times$ number of users

Pills $=$ number of pills $/ 100$

Condoms $=$ number of condoms $/ 100$ 
Injectables $=$ number of injectables $/ 4$

Norplant $=$ number of Norplant capsules X 5 .

\section{Sensitivity analysis}

Sensitivity analyses were conducted regarding the value of the ICER of CYP and of FP visits for mobile clinics compared to static clinics. The parameters varied in the sensitivity analysis included: total costs of mobile clinics, total costs of static clinics and CYP or FP visits for mobile and static clinics. Because the current Cost Effectiveness Analysis (CEA) based on the assumption that mobile clinics are more cost effective than static clinic, so sensitivity analysis was done to assess for uncertainty using @Risk software, where statistical probability distributions of the input variables (costs, CYP and FP visits of mobile and static clinics) were used. Sensitivity was measured based on the amount of variance in the outputs caused by variations in inputs. The iterations were repeated 1000 times to show the range of expected results for the ICERs. Histograms and tornado diagrams were used to display the graphical output.

\section{Results}

\section{Cost measures}

Costs were calculated from the provider perspective. The total costs of the 15 mobile clinics offering family planning or reproductive health services in Assiut Governorate were nearly 1.5 times higher than the costs of a corresponding number of the static clinics; the mobile clinics cost more than two hundred thousand US Dollars $(\$ 233,855)$ from November 1, 2009 till the end of October, 2010 compared to nearly more than one hundred thousand US Dollars $(\$ 118,256)$ cost at the matching static clinics in the same districts where the mobile clinics serve during the same period (Table, 2). The mobile clinic teams spent almost all of their time offering family planning services (minimum of $77.2 \%$ to maximum of $99.8 \%$ ) while the static clinic staff allocated between $8.5 \%$ and $34.1 \%$ of their time to family planning service delivery.
The total aggregated acquisition costs of the contraceptive commodities and other supplies and materials that were used in the family planning clinics were higher in the static clinics $(\$ 27,961$ and \$6,504 respectively for all static clinics aggregated) than in the mobile clinics $(\$ 17,673$ and $\$ 5,224$ respectively for all mobile clinics aggregated) (Table 2). The capital costs of the 15 mobile clinics $(\$ 68,058)$ were higher than the capital costs of the 15 comparison static clinics $(\$ 33,956)$ (Table 2). The total annual operating costs for all mobile clinics was $\$ 19,971$ (fuel + oil + maintenance) (Table 2) with a mean of $\$ 1,331$ per each mobile clinic during the study period. On the other hand, the total annual operating costs for all static clinics $=\$ 327$ (Table 2) with a mean of $\$ 22$ per each static clinic during the study period.

Table 2: Summary Cost Measures of Static and Mobile Clinics, Assiut, Egypt, 2010.

\begin{tabular}{|c|c|c|}
\hline Cost measure & $\begin{array}{l}15 \quad \text { Static } \\
\text { clinics }(\text { US \$) }\end{array}$ & $\begin{array}{l}15 \quad \text { Mobile } \\
\text { clinics }(\text { US \$) }\end{array}$ \\
\hline $\begin{array}{l}\text { Total salaries \& } \\
\text { incentives }\end{array}$ & $\$ 49,508$ & $\$ 122,928$ \\
\hline $\begin{array}{l}\text { Total commodities } \\
\text { costs }\end{array}$ & $\$ 27,961$ & $\$ 17,673$ \\
\hline $\begin{array}{l}\text { Total supplies \& } \\
\text { materials }\end{array}$ & $\$ 6,504$ & $\$ 5,224$ \\
\hline Total capital costs & $\$ 33,956$ & $\$ 68,058$ \\
\hline $\begin{array}{l}\text { Total maintenance } \\
\text { costs }\end{array}$ & $\$ 327$ & $\$ 14,693$ \\
\hline Total fuel costs & $\mathrm{Na}^{*}$ & $\$ 3,882$ \\
\hline Total oil costs & $\mathrm{Na}^{*}$ & $\$ 1,397$ \\
\hline Grand total & $\$ 118,256$ & $\$ 233,855$ \\
\hline
\end{tabular}

*NA: Non applicable

\section{Couple years of protection}

The total number of contraceptive commodity units offered to women at the mobile clinics $(36,169)$ was less than the total number of contraceptive methods offered to women at the static clinics $(44,006)$. On the other hand, the CYPs for contraceptive methods offered to women at the mobile clinics $(38,863)$ were higher than the CYPs for contraceptive methods offered to women at the static clinics $(12,964)$ (Table, 3$)$.

\section{Family planning visits}

There were 25,685 family planning visits to the 15 
mobile clinics with the mean number of family planning visits /mobile clinic of 1,712.3. In comparison, the total number of family planning visits at the static clinics was 30,714 (Table, 3) with the mean number of family planning visits /static clinic of 2,048 . So, the number of family planning visits is higher in the static clinics than in the mobile clinics.

Table 3: Summary Data for Incremental Cost Effectiveness Measures, Assiut, Egypt, 2010.

\begin{tabular}{lll}
\hline Category & $\begin{array}{l}\mathbf{1 5} \text { Static } \\
\text { clinics }\end{array}$ & $\mathbf{1 5}$ Mobile clinics \\
\hline Total costs (\$US) & $\$ 118,256$ & $\$ 233,855$ \\
Total CYPs & 12,964 & 38,863 \\
$\begin{array}{l}\text { Total number of FP } \\
\text { visits }\end{array}$ & 30,714 & 25,685 \\
$\begin{array}{l}\text { Change in costs } \\
\text { Change in CYPs }\end{array}$ & $-\$-115,599$ & \\
$\begin{array}{l}\text { Change in number of } \\
\text { FP visits }\end{array}$ & $-25,899$ & \\
ICER for CYP & $-5,029$ & \\
ICER for FP visits & Dominated $(-\$ 22.99)$ \\
\hline
\end{tabular}

\section{Incremental cost-effectiveness ratios}

The ICER per FP visit showed that static clinics dominated mobile clinics by offering more visits for less money. However the mobile clinics offered more CYPs for more money and the ICER was $\$ 4.46$ per additional CYP from mobile clinics compared to static clinics.

\section{Sensitivity analysis}

In order to assess uncertainty in ICER, sensitivity analyses were done to examine the impact of alterations in costs, CYP or FP visits on mean ICER of CYP and mean ICER of FP visits. The main drivers for ICER of CYP are the total CYP output measures of mobile and static clinics. Variations in the CYP of mobile clinics (2.5 to 6.4) and static clinics (2.6 to 6.3) altered the ICER for CYP from \$2 -6 (Figures $1 \&$ 2). The main drivers for ICER of FP visits were total costs of mobile clinics followed by total FP visits of the mobile clinics (Figure 2).

\section{Discussion}

In Egypt, family planning services are offered through the static and mobile clinics. The value of mobile clinics in providing family planning services especially to the remote rural poor women is evident in other studies ${ }^{1-3,12-14}$.

This paper shows that the heavy subsidies applied in the mobile clinics resulted in a larger uptake of long acting methods. Compared to the static clinics that charge fees for birth control, the government's mobile clinic program is able to offer additional family planning coverage that only costs $\$ 4.46$ per CYP.

All the contraceptive methods at the mobile clinics are $100 \%$ subsidized, except for the pills. In contrast, the static clinic offers only partial subsidies. The acquisition cost of the contraceptive commodities and other supplies and materials that were used in the family planning clinics were higher in the static clinics $(\$ 34,465)$ than in the mobile clinics $(\$ 22,897)$. This cost difference is attributed to the higher quantity of supplies and materials and short-acting methods used by the static clinic. However, the unit price of the same types of supplies and materials used in both clinics was the same.

The capital costs of the 15 mobile clinics $(\$ 68,058)$ were higher than the capital costs of the 15 comparison static clinics $(\$ 33,956)$. The main reason for this discrepancy is the replacement costs of the mobile clinics where the replacement costs of one vehicle $=\$ 90,695$. On the other hand, rental costs for the static clinics are modest because all the clinics lie in rural areas where usually the rent is not high. The rental costs were the same for all static clinics except for 2 clinics; Dyerout Medical Center and Al-Ghanayem Medical Center where the rental costs were higher.

Since most FP services offered by the mobile clinics are free of charge including IUD insertion, there was higher IUD utilization at the mobile clinics. Because the women are using more long acting methods at the mobile clinics, there are fewer visits despite higher costs. Prior research showed that utilization of mobile clinics is affected by some social factors rather than financial factors. In a former study that explored lower utilization of mobile clinics, it was noted that rumors and social stigma are higher at mobile clinics because unlike static facilities the mobile clinics offer only family planning services ${ }^{5}$. Moreover, some clients have more confidence in static clinics due to the 

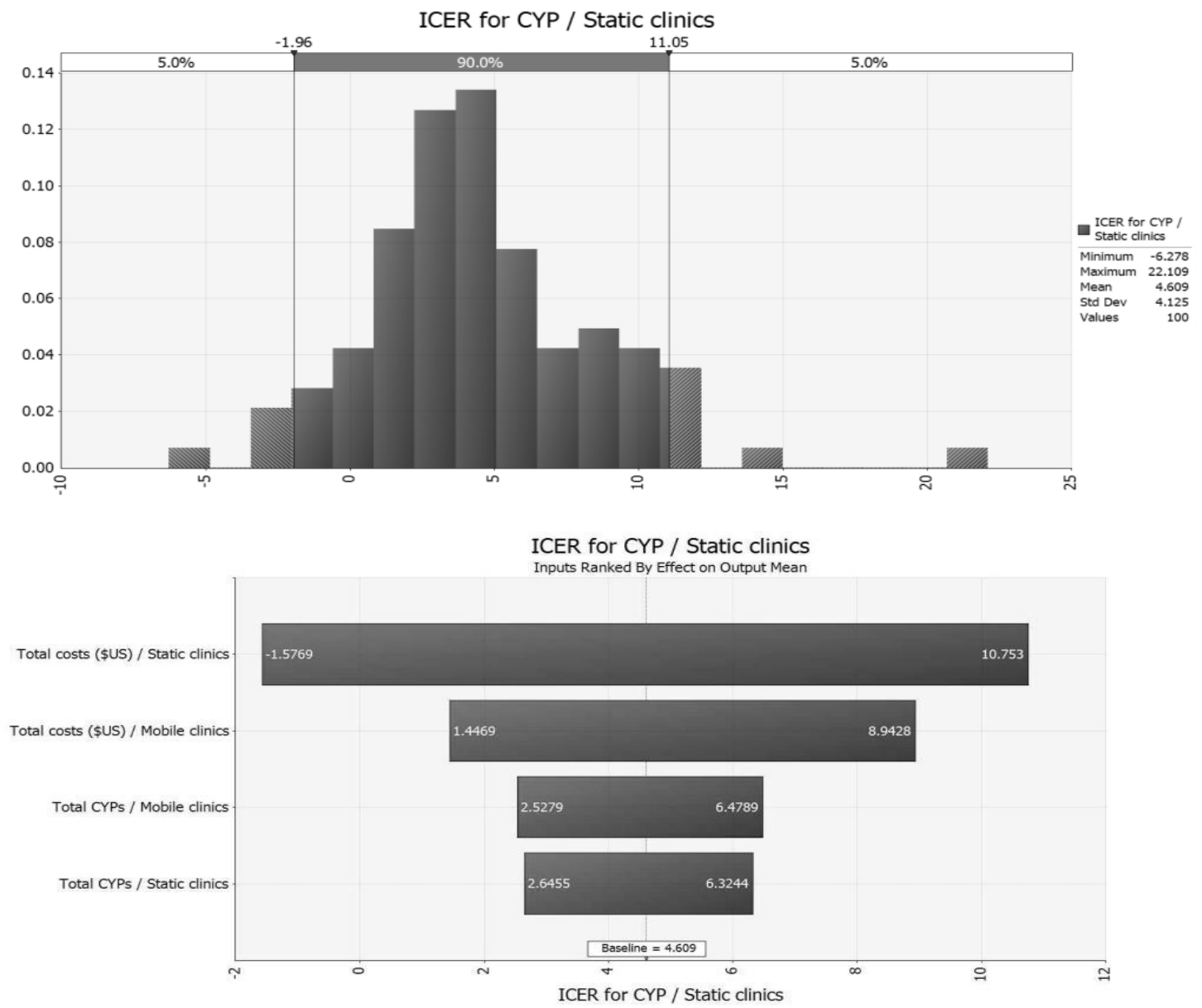

Figure 1: Sensitivity Analysis: Histogram and Tornado Diagrams Showing Impact of Parameter Changes on ICER of CYP for Mobile Versus Static Clinics, Assiut, Egypt, 2010.

availability of the same doctor each time they visit the static clinic, the wider spectrum of services, and the fees charged at the static clinics make some women more confident in the quality of services offered compared to the free services offered at the mobile clinics 5 .

Salaries and consultation fees of health care providers offering FP services represent the main bulk of incurred costs in our study as in other CEA studies ${ }^{12-16}$. This finding was true for both mobile and static clinics. Increase in salaries could be affected by the number of patients attending the clinics $^{14}$ or the number of working days as well as the range of offered services in each clinic per day. However, in our study, there was a large difference in the total costs of the mobile versus the static clinics although the labor costs at the static clinics were similar to the mobile clinics. This could be explained by the fact that capital costs of mobile clinics are higher than those of the static clinics and the time allocation of the staff members working at these clinics in offering FP methods. Mobile clinic staffs do almost nothing else but family planning so the majority of their labor costs are attributable to family planning unlike staff at static facilities ${ }^{4}$. Moreover, the capital costs of the mobile clinics were high because the replacement costs of a mobile clinic vehicle is high compared to the rental space costs for a static clinic in rural Egypt.

The attractive cost effectiveness of mobile clinics may have less to do with their mobility and more to 

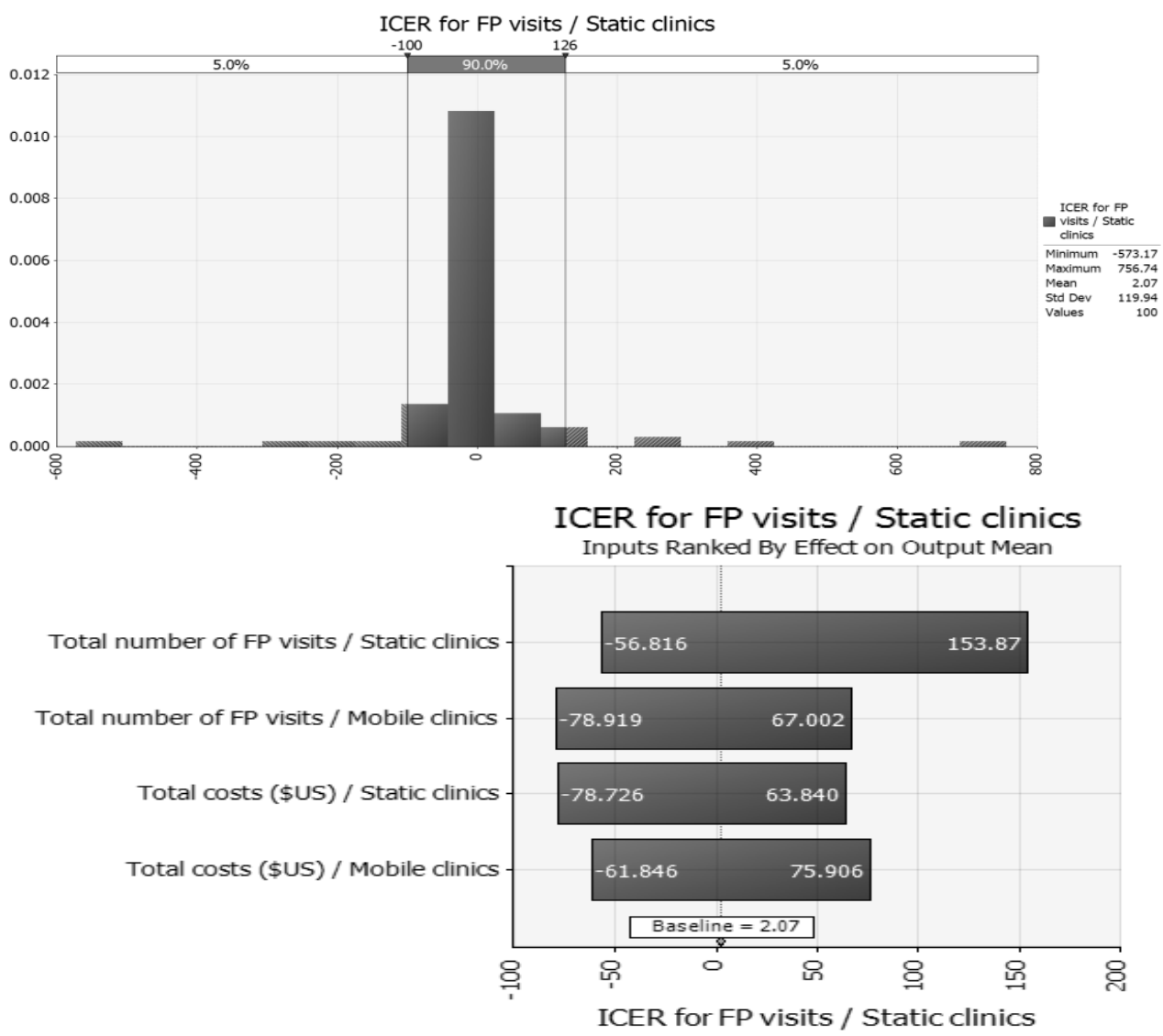

Figure 2: Sensitivity Analysis: Histogram and Tornado Diagrams Showing Impact of Parameter Changes on ICER of FP Visits for Mobile Versus Static Clinics, Assiut, Egypt, 2010.

do with the attractive pricing of long acting methods which allowed mobile clinics to achieve higher CYP coverage. Unfortunately, there were no static clinics that offered free long acting methods to use to test this hypothesis. Given the high capital cost of mobile clinics, an experiment to offer free IUDs in static clinics may reveal that this is an even more attractive strategy than tying free IUDs to capital and labor intensive mobile clinics. Further experimental studies are needed especially in low and middle income countries to assess the impact of mobile clinics on women and child health ${ }^{17}$.

\section{Conclusion}

The findings of the present study showed that mobile clinics offer more CYP than corresponding static clinics and that one extra CYP for contraception in Assiut Governorate costs $\$ 4.46$ if women obtained the service from the static clinics compared to the mobile clinic. The discrepancy could be because mobile clinics emphasized more IUDs and fewer condoms compared to static clinics. Despite the sensitivity of cost-effectiveness ratio, the range across which ICER varied didn't alter any of the results. With funding cuts and economic situation, Egypt's Government will face financial challenges to maintain the family planning program's generosity. The family planning program might be able to achieve the benefits of higher CYPs without as much cost if it simply subsidizes the price of IUDs without the added expenses of mobile clinics. Operational studies to confirm these findings would be necessary.

\section{Limitations}

Given multiple sources of data collection (at the 
local and peripheral level), records, meetings and telephone calls, there was a scattering and multiplicity of the data. Due to different categories of the health providers and different numbers of employment years it was impossible to aggregate the salaries and incentives of the similar types of employees. The large number of mobile clinics (15) and static clinics (15) included in the study drew an extra effort on data collection, unification, comparison and analysis. Additionally, administrative costs were not included in this study for either static or mobile clinics. Also, it is noteworthy to mention that time and transportation costs of the clients were not included in the analysis.

\section{Conflict of Interest}

No conflict of interest was declared by all authors.

\section{Acknowledgments}

Thanks are due to Dr. Mamdouh Abd-AlMawgoud; Undersecretary of MOHP, and Dr. Somaya Antar, Family Planning Director at local MOHP, Assiut Governorate, Egypt for their support and facilitating data collection. In addition, thanks are due to Dr. Nadia Diamond-Smith, University of California, for editing an earlier version of the study. Thanks are due to all the personnel who helped in data collection and entry and for all the study participants and interviewee. Thanks are due to the Gates Institute at Johns Hopkins School of Public Health for funding this research.

\section{Contribution of Authors}

Omaima El-Gibaly conceived, designed the study and helped in taking approvals for data collection as well as in revising the manuscript. David Bishai conceived, designed the study, analyzed the data, prepared and revised the manuscript. Ghada AlAttar collected, analyzed the data, prepared and revised the manuscript. All authors approved the final version of the manuscript.

\section{References}

1. ACCP Delivering clinical services and strengthening linkages at Planning and implementing cervical cancer prevention and control programs: A Manual for managers, Seattle; 2004, Chapter 6: 81-125.

2. Simelela N. Women's access to modern methods of fertility regulation. International J Gynecol Obstet 2006; 94: $292-300$.

3. Vos JJ, Borgdorff M and Kachidza EG. Cost and output of mobile clinics in a commercial farming area in Zimbabwe, Soc Sci Med 1990; 31 (11): 1207 - 1211.

4. El-Zanaty F and Hamed R. Sustainability of mobile clinics in reproductive health and family planning service delivery, El-Zanaty \& Associates, Research Management Unit, National Population Council, Egypt, 2001; Pages: 1 - 2, 9 - 10, 19 and 48.

5. El-Gibaly OMH, Moftah F, Salah M and Al-Attar GST. Have mobile clinics increased access to family planning methods in Assiut Governorate? Assiut Med J 2008; 32 Conference Issue 8-11 Mar: 49-57.

6.El-Zanaty F and Way A, Egypt Demographic and Health Survey 2005, Cairo, Egypt: Ministry of Health and Population, National Population Council, El-Zanaty and Associates, and ORC Macro, 2006.

7 .El-Zanaty F and Way A, Egypt Demographic and Health Survey 2008, Cairo, Egypt: Ministry of Health, ElZanaty and Associates, and Macro International, 2009.

8. Ministry of Health and Population [Egypt], El-Zanaty and Associates [Egypt] and ICF International. 2015. Egypt Demographic and Health Survey 2014. Cairo, Egypt and Rockville, Maryland, USA: Ministry of Health and Population and ICF International.

9. Antar S. Operational policy of work schedule of mobile clinics in Assiut Governorate. Ministry of Health and Population, 2014.

10. Janowitz B and Bratt JH. Methods for costing family planning services, UNFPA. FHI 1994; Chapter 4 and chapter 5: $23-48$.

11. MOHP. Training course to ensure continuity of family planning methods availability. Supply and demand." MOHP 2008; Chapter 4: 83.

12. Coeytaux F. An evaluation of the cost-effectiveness of mobile family planning services in Tunisia. Stud Fam Plann 1989; 20 (3): 158-169.

13. McGuire A and Hughes D. The cost effectiveness of family planning service provision. J Pub Heal Med 1996; 18 (2): 189 - 196.

14. Schnippel K, Lince-Deroche N, van den Handel T, Molefi S, Bruce S and Firnhaber C. Cost evaluation of reproductive and primary health care mobile service delivery for women in two rural districts in South Africa. PLoS ONE [Electronic Resource] 2015; 10 (3):e0119236.

15. Vance G and Bratt J. Mobile outreach services for family planning in Tanzania: an overview of financial costs. The RESPOND Project Study Series: Contributions to Global Knowledge 2013; 14 (15).

16. Babu KS, Townsend JW and RamaRao S. Evaluation of mobile education and service units in increasing 
Al-Attar et al.

accessibility and acceptability of family planning methods, India. Final report. Jaipur, India, Indian Institute of Health Management Research 1995; 28.

17. Abdel-Aleem H, El-Gibaly OMH, EL-Gazzar AFES and
Cost-Effectiveness of Family Planning Services

Al-Attar GST. Mobile clinics for women's and children's health. Cochrane Database of Systematic Reviews 2016; 8. Art. No.: CD009677. DOI: 10.1002/14651858.CD009677.pub2. 